\title{
MINDO/3 Study of the Protonation of Phenol and Methylphenols
}

\author{
M. Eckert-Maksić \\ Department of Organic Chemistry and Biochemistry, „Rudjer Bošković” Institute, Zagreb, \\ Yugoslavia
}

Z. Naturforsch. 37a, 688-696 (1982); received March 31, 1982

\begin{abstract}
The electronic and molecular structures of phenol and its ortho- meta-, and para-methyl derivates as well as their conjugate acids were studied by the semiempirical MINDO $/ 3$ method. The calculations predict substantial structural changes upon protonation. Theoretically predicted protonation sites are in very good agreement with experimentally observed modes of protonation under superacidic conditions.
\end{abstract}

\section{Introduction}

The question of the prefered sites of protonation of hydroxybenzenes has been much discussed from both experimental [1-4] and theoretical [5-7] points of view. In superacid solutions these bases protonate on oxygen or ring carbon $[1,2]$. The relative extent of $\mathrm{O}$ - and $\mathrm{C}$-protonation and the position of C-protonation is dependent on several factors such as electronic structure of the base, acidity and solvation properties of the medium and temperature $[2,3]$. Theoretical studies were mainly devoted to exploring the intrinsic basicities of different positions in the molecule [5,6]. There has also been considerable interest on the relationship between proton affinities and core ionization energies [7]. In most calculations standard geometries or partly optimized structures for the conjugate acids have been used. This simplified treatment is qualitatively valid as a first approximation, it is, however, generally accepted that the bare proton perturbs the molecule to a considerable extent. A good illustrative example is provided by the protonation of the ring oxygen in methylsydnone, which leads to ring opening and formation of a ketone like chain [8]. Therefore, it seemed desirable to reinvestigate the protonation of some of hydroxybenzenes in more detail, using a method which enables, albeit approximate, full geometry optimization of the ions involved. Concomitantly, we performed MINDO/3 calculations [9] on protonated forms of phenol (1) and its ortho-(2), meta-(3) and para-(4) methyl derivatives. Essential results are reported here.

Reprint requests to Dr. M. Eckert-Maksić, Department of Organic Chemistry and Biochemistry, P.O. Box 1016, Rudjer Bošković Institute, 41001 Zagreb/Yugoslawia.

\section{Computational Procedure}

The geometries of all species were fully optimized with respect to all independent structural parameters. Computations were performed on the Univac 1100 Computer at the University Computational Centre in Zagreb.

\section{Results and Discussion}

\section{Geometries}

The calculated structural parameters of phenol and its potential conjugate acids are summarized in Table 1. The calculated carbon-carbon bond lengths for neutral phenol are overestimated by $0.007-0.027 \AA$ relative to the experimentally determined value $(1.396 \AA)$ based on the assumption of a regular hexagon [10] for the benzene moiety. Systematic studies of the molecular geometry of a number of substituted benzenes have, however, shown that replacement of a hydrogen atom by other atoms or functional groups may lead to a substantial distortions of the C-hexagon from perfect $\mathrm{D}_{6 \mathrm{~h}}$ symmetry [11]. The most pronounced changes occur in the bond lengths and angles nearest to the point of fusion. The effect has been rationalized in terms of either hybridization effects or valenceshell electron pair repulsion $[11,12]$. The importance of the conjugative interaction between substituent and ring, where possible, has also been pointed out.

An analysis of the hybridization parameters of phenol as calculated by the MINDO/3 charge density matrix $[8,13,14]$ indicates a pronounced decrease of s-character $(\sim 23 \%)$ in the hybrid orbital of the $\mathrm{C}_{1}$ atom directed toward oxygen relative to the canonical $\mathrm{sp}^{2}$ value. This is in accordance with the well known Bent-Walsh rule $[15,16]$, which 
Table 1. MINDO/3 calculated bond distances $(\AA)$ and bond angles (deg) of phenol and protonated phenols.

\begin{tabular}{llllll}
\hline Bond & \multicolumn{3}{c}{ Bond distances ( $(\mathrm{A})$ and bond angles (deg) } \\
Angle & Molecule or ion
\end{tabular}

Table 2. MINDO/3 calculated geometries for cresols 2-4 and their 0 -protonated and the most stable ring protonated ions.

\begin{tabular}{llll}
\hline Bond & Bond distances $(\AA)$ and bond angles $(\mathrm{deg})$ \\
Angle & Molecule or ion
\end{tabular}


Table 2, contin.

$\begin{array}{llll}\text { Bond } & \text { Bond distances }(\AA) \text { and angles }(\mathrm{deg}) \\ \text { Angle } & \text { Molecule or ion }\end{array}$

\begin{tabular}{llll}
\hline Bond & Bond distances $(\AA)$ and angles $(\mathrm{deg})$ \\
$\mathrm{Angle}$ & & \\
& &
\end{tabular}


states that an electronegative substituent prefers a higher contribution of the p-orbital in the partner hybrid of the neighbouring atom. The relatively high $\pi$-bond order $(0.312)$ for this bond is reflected in the relatively short bond distance of $1.326 \AA$. The $\sigma$-hybrid orbitals directed from $\mathrm{C}_{1}$ to $\mathrm{C}_{2}$ and $\mathrm{C}_{6}$, respectively, exhibit a substantial increase of the s-character, as well as decrease in the $\pi$-overlap population $(0.620)$ relative to the remaining ring bonds $(\sim 0.67)$, an amount which, in turn, corresponds to the $\pi$-bond order in benzene. The resulting bond length is a compromise between the two opposing effects: shortening due to the increase in s-content and lengthening because of the decrease in $\pi$-electron density. The former contribution is outweighted by the latter, leading to the lengthening of the $\mathrm{C}_{1} \mathrm{C}_{2}$ and $\mathrm{C}_{1} \mathrm{C}_{6}$ bonds to $1.423 \AA$ and $1.420 \AA$, respectively. The systematic differencies occuring in the values of bond lengths and angles of the ring (reflected also in the $\pi$-overlap populations) suggest a greater contribution from the canonical form $\mathbf{A}$ than from $\mathbf{B}$. The same conclusion follows from the pattern of the calculated charge densities (Table 3).
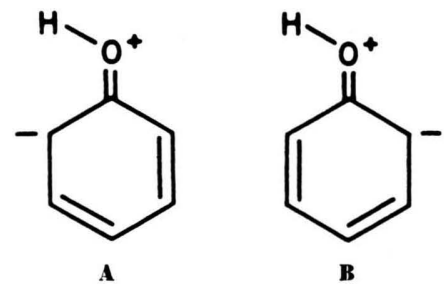

Protonation of phenol at each of the considered positions causes substantial geometric distortions (relative to the neutral phenol). On conversion to the oxonium ion (1a) the parameters related to the oxygen are most affected. Thus the $\mathrm{C}_{1} \mathrm{O}_{7} \mathrm{H}$ angle is enlarged by about $10^{\circ}$ relative to unprotonated base. The $\mathrm{C}_{1} \mathrm{O}_{7}$ bond length increases by $0.07 \AA$, in accord with a drastic reduction in $\pi$-overlap population (Table 3). Among the bonds of the ring the largest changes show those terminating at the $\mathrm{OH}$ substituted ring carbon. These are shortened by about $0.02 \AA$ relative to those in neutral phenol as a consequence of the increased $\pi$-bond overlap population and increase of the average s-character in the orbitals of the $\sigma$-bonds. The rest of the ring fragment remains virtually unchanged.

The major change in the ring protonated ions is exhibited in the lengthening of the bond distances terminated at the protonated carbon $(\sim 0.09 \AA)$. The observed changes can be well understood in terms of the rehybridization caused by protonation. In particular, the mentioned lengthening is a consequence of the decrease in s-character of the relevant carbon-carbon $\sigma$-hybrid orbitals. More specifically, the s-character of the hybrid bond orbitals $\psi\left(\mathrm{C}_{5}-\mathrm{C}_{4}\right)$ and $\psi\left(\mathrm{C}_{4}-\mathrm{C}_{5}\right)$ in ion $1 \mathrm{~d}$ as calculated from the MINDO/3 charge density matrix is $32.3 \%$ and $27.5 \%$ respectively; while the corresponding values in neutral phenol are practically both equal to $33.3 \%$. The same holds for the $\mathrm{C}_{4}-\mathrm{C}_{3}$ bond. In the ion $1 \mathrm{~d}$ this bond is described by $27.8-32.2$ (in \%) noninteger hybridization parameters, as compared to $33.3-33.3 \%$ in 1 . The slight increase of the average s-character of the hybrids forming the CCC angle at the protonated carbon $\left(\psi\left(\mathrm{C}_{4}-\mathrm{C}_{3}\right)\right.$ and $\psi\left(\mathrm{C}_{4}-\mathrm{C}_{5}\right)$ hybrids in the case of ion $\left.1 \mathrm{~d}\right)$ relative to the canonical $\mathrm{sp}^{3}$ value is reflected in the distortion of this angle from the pure tetrahedral value $\left(114.5^{\circ}\right.$ in 1d), yielding a characteristic shift toward $120^{\circ}$.

The $\pi$-overlap population between the $\mathrm{CH}_{2}$ and its carbon neighbours, although remarkably reduced when compared with the corresponding value in phenol, is not negligible, indicating a certain amount of hyperconjugative interaction between the $\mathrm{CH}_{2}$ group and the rest of the molecule. In addition to a drastic changes in the $\mathrm{C}-\mathrm{C}$ bond distances adjacent to the protonated carbon, protonation in the ring leads to a shortening of the $\mathrm{C}-\mathrm{C}$ bonds in the pentadienyl part of the molecule (by $0.04 \AA$ ), while the $\mathrm{C}-\mathrm{C}$ bonds to the para carbon are lengthened by $0.02 \AA$ as compared with the neutral base. Both effects are compatible with the change in $\pi$-bond overlap populations as indicated in Table 3. Finally, there is an appreciable increase in the double bond character of the $\mathrm{C}_{1} \mathrm{O}_{7}$ bond in the ions $\mathbf{1 b}$ and $\mathbf{1 d}$ suggesting substantial contributions from the corresponding quinoid valence bond structure in the ground states of these ions.

It should be mentioned that the main features of the ring geometry of the ions $\mathbf{1} \mathbf{b}-\mathbf{1} \mathbf{d}$ are compatible with the structure of the heptamethylbenzenium ion as determined by X-ray diffraction [17].

A comparison of the calculated equilibrium geometries for cresols with that of the parent phenol indicates clearly that the methyl substitution gives rise for further ring deformations. They encompass a lengthening of the $\mathrm{C}-\mathrm{C}$ bonds terminating at the point of the methyl substitution relative to the cen- 
Table 3. Formal atomic charge and $\pi$-overlap population analysis of the phenols $1-4$ and their oxygen and the most stable ring protonated ions.

\begin{tabular}{lccc}
\hline Base or ion & $\begin{array}{c}\text { Atom } \begin{array}{l}\text { Formal } \\
\text { atomic } \\
\text { charge }\end{array} \\
\text { nargerlap }\end{array}$ \\
\hline
\end{tabular}

\begin{tabular}{cccc}
\hline Base or ion & $\begin{array}{c}\text { Atom } \begin{array}{l}\text { Formal } \\
\text { atomic } \\
\text { charge }\end{array} \\
\text { chand }\end{array}$ & Bond & $\begin{array}{l}\pi \text {-overlap } \\
\text { populat. }\end{array}$ \\
\hline
\end{tabular}

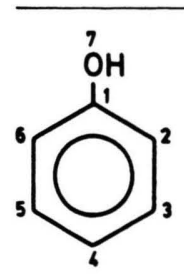

$\begin{array}{lrll} & & & \\ \mathrm{C}_{1} & 0.396 & \mathrm{C}_{1} \mathrm{C}_{2} & 0.631 \\ \mathrm{C}_{2} & -0.129 & \mathrm{C}_{2} \mathrm{C}_{3} & 0.666 \\ \mathrm{C}_{3} & 0.072 & \mathrm{C}_{3} \mathrm{C}_{4} & 0.668 \\ \mathrm{C}_{4} & -0.074 & \mathrm{C}_{4} \mathrm{C}_{5} & 0.654 \\ \mathrm{C}_{5} & 0.081 & \mathrm{C}_{5} \mathrm{C}_{6} & 0.681 \\ \mathrm{C}_{6} & -0.166 & \mathrm{C}_{1} \mathrm{C}_{6} & 0.620 \\ \mathrm{O}_{7} & -0.447 & \mathrm{C}_{1} \mathrm{O}_{7} & 0.312\end{array}$

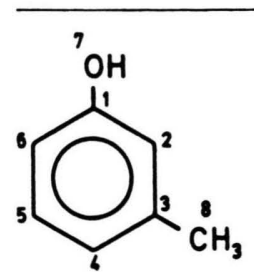

\begin{tabular}{lrll}
\hline $\mathrm{C}_{1}$ & 0.394 & $\mathrm{C}_{1} \mathrm{C}_{2}$ & 0.626 \\
$\mathrm{C}_{2}$ & -0.137 & $\mathrm{C}_{2} \mathrm{C}_{3}$ & 0.666 \\
$\mathrm{C}_{3}$ & 0.079 & $\mathrm{C}_{3} \mathrm{C}_{4}$ & 0.640 \\
$\mathrm{C}_{4}$ & -0.080 & $\mathrm{C}_{4} \mathrm{C}_{5}$ & 0.673 \\
$\mathrm{C}_{5}$ & 0.079 & $\mathrm{C}_{5} \mathrm{C}_{6}$ & 0.663 \\
$\mathrm{C}_{6}$ & -0.164 & $\mathrm{C}_{1} \mathrm{C}_{6}$ & 0.630 \\
$\mathrm{O}_{7}$ & -0.444 & $\mathrm{C}_{1} \mathrm{O}_{7}$ & 0.310 \\
$\mathrm{C}_{8}$ & 0.076 & &
\end{tabular}<smiles>Oc1ccccc1</smiles>

$\begin{array}{lrll}\mathrm{C}_{1} & 0.271 & \mathrm{C}_{1} \mathrm{C}_{2} & 0.657 \\ \mathrm{C}_{2} & -0.071 & \mathrm{C}_{2} \mathrm{C}_{3} & 0.664 \\ \mathrm{C}_{3} & 0.083 & \mathrm{C}_{3} \mathrm{C}_{4} & 0.666 \\ \mathrm{C}_{4} & -0.002 & \mathrm{C}_{4} \mathrm{C}_{5} & 0.666 \\ \mathrm{C}_{5} & 0.083 & \mathrm{C}_{5} \mathrm{C}_{6} & 0.663 \\ \mathrm{C}_{6} & -0.071 & \mathrm{C}_{1} \mathrm{C}_{6} & 0.657 \\ \mathrm{O}_{7} & -0.261 & \mathrm{C}_{1} \mathrm{O}_{7} & 0.160\end{array}$

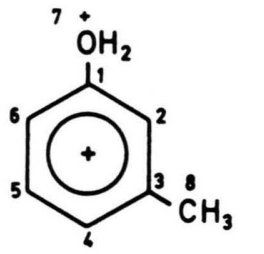
$\begin{array}{ll}\mathrm{C}_{1} & 0.280\end{array}$ 0.262
0.041

$\mathrm{C}_{1} \mathrm{C}_{2} \quad 0.661$

$\begin{array}{lrll}\mathrm{C}_{3} & 0.121 & \mathrm{C}_{3} \mathrm{C}_{4} & 0.648 \\ \mathrm{C}_{4} & -0.029 & \mathrm{C}_{4} \mathrm{C}_{5} & 0.674\end{array}$

$\begin{array}{llll}\mathrm{C}_{5} & 0.089 & \mathrm{C}_{5} \mathrm{C}_{6} & 0.657\end{array}$

$\begin{array}{llll}\mathrm{C}_{6} & -0.082 & \mathrm{C}_{1} \mathrm{C}_{6} & 0.656\end{array}$

0.160

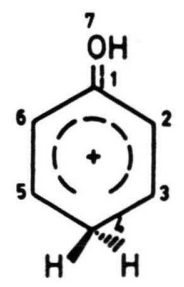

$\begin{array}{lrll}\mathrm{C}_{1} & 0.621 & \mathrm{C}_{1} \mathrm{C}_{2} & 0.406 \\ \mathrm{C}_{2} & -0.166 & \mathrm{C}_{2} \mathrm{C}_{3} & 0.878 \\ \mathrm{C}_{3} & 0.165 & \mathrm{C}_{3} \mathrm{C}_{4} & 0.234 \\ \mathrm{C}_{4} & -0.018 & \mathrm{C}_{4} \mathrm{C}_{5} & 0.237 \\ \mathrm{C}_{5} & 0.189 & \mathrm{C}_{5} \mathrm{C}_{6} & 0.869 \\ \mathrm{C}_{6} & -0.211 & \mathrm{C}_{1} \mathrm{C}_{6} & 0.415 \\ \mathrm{O}_{7} & -0.350 & \mathrm{C}_{1} \mathrm{O}_{7} & 0.582\end{array}$

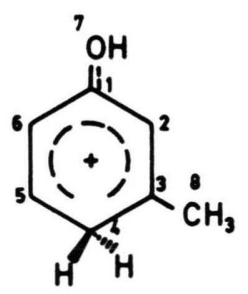

$\begin{array}{ll}\mathrm{C}_{1} & 0.620\end{array}$

$\mathrm{C}_{1} \mathrm{O}_{7} \quad 0.160$<smiles>Cc1ccccc1O</smiles>

$\begin{array}{lrll}\mathrm{C}_{1} & 0.384 & \mathrm{C}_{1} \mathrm{C}_{2} & 0.607 \\ \mathrm{C}_{2} & -0.166 & \mathrm{C}_{2} \mathrm{C}_{3} & 0.666 \\ \mathrm{C}_{3} & 0.058 & \mathrm{C}_{3} \mathrm{C}_{4} & 0.660 \\ \mathrm{C}_{4} & -0.018 & \mathrm{C}_{4} \mathrm{C}_{5} & 0.665 \\ \mathrm{C}_{5} & 0.081 & \mathrm{C}_{5} \mathrm{C}_{6} & 0.664 \\ \mathrm{C}_{6} & -0.165 & \mathrm{C}_{1} \mathrm{C}_{6} & 0.636 \\ \mathrm{O}_{7} & -0.448 & \mathrm{C}_{1} \mathrm{O}_{7} & 0.316 \\ \mathrm{C}_{8} & 0.121 & & \end{array}$<smiles>Cc1ccccc1O</smiles>

$\begin{array}{lrll}\mathrm{C}_{1} & 0.251 & \mathrm{C}_{1} \mathrm{C}_{2} & 0.650 \\ \mathrm{C}_{2} & -0.028 & \mathrm{C}_{2} \mathrm{C}_{3} & 0.672 \\ \mathrm{C}_{3} & 0.056 & \mathrm{C}_{3} \mathrm{C}_{4} & 0.653 \\ \mathrm{C}_{4} & 0.003 & \mathrm{C}_{4} \mathrm{C}_{5} & 0.680 \\ \mathrm{C}_{5} & 0.079 & \mathrm{C}_{5} \mathrm{C}_{6} & 0.641 \\ \mathrm{C}_{6} & -0.069 & \mathrm{C}_{1} \mathrm{C}_{6} & 0.654 \\ \mathrm{O}_{7} & -0.264 & \mathrm{C}_{1} \mathrm{O}_{7} & 0.157 \\ \mathrm{C}_{8} & 0.121 & & \end{array}$

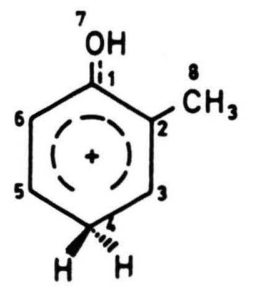
$\begin{array}{llll}\mathrm{C}_{1} & 0.601 & \mathrm{C}_{1} \mathrm{C}_{2} & 0.390\end{array}$
$\begin{array}{llll}\mathrm{C}_{2} & -0.104 & \mathrm{C}_{2} \mathrm{C}_{3} & 0.870\end{array}$
$\begin{array}{llll}\mathrm{C}_{3} & 0.117 & \mathrm{C}_{3} \mathrm{C}_{4} & 0.233\end{array}$
$\begin{array}{llll}\mathrm{C}_{4} & -0.011 & \mathrm{C}_{4} \mathrm{C}_{5} & 0.238\end{array}$
$\begin{array}{llll}\mathrm{C}_{5} & 0.187 & \mathrm{C}_{5} \mathrm{C}_{6} & 0.867\end{array}$
$\begin{array}{llll}\mathrm{C}_{6} & -0.210 & \mathrm{C}_{1} \mathrm{C}_{6} & 0.419\end{array}$
$\begin{array}{llll}\mathrm{O}_{7} & -0.358 & \mathrm{C}_{1} \mathrm{O}_{7} & 0.585\end{array}$

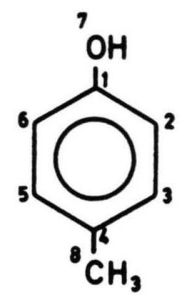
$\begin{array}{ll}\mathrm{C}_{1} & 0.393\end{array}$
$-0.126$
0.065
$-0.060$
0.073
$-0.163$
$-0.442$

$\begin{array}{ll}\mathrm{C}_{1} \mathrm{C}_{2} & 0.624 \\ \mathrm{C}_{2} \mathrm{C}_{3} & 0.676 \\ \mathrm{C}_{3} \mathrm{C}_{4} & 0.651 \\ \mathrm{C}_{4} \mathrm{C}_{5} & 0.641 \\ \mathrm{C}_{5} \mathrm{C}_{6} & 0.686 \\ \mathrm{C}_{1} \mathrm{C}_{6} & 0.619 \\ \mathrm{C}_{1} \mathrm{O}_{7} & 0.315\end{array}$

0.106

$\begin{array}{ll}\mathrm{C}_{1} \mathrm{C}_{2} & 0.447 \\ \mathrm{C}_{2} \mathrm{C}_{3} & 0.832 \\ \mathrm{C}_{3} \mathrm{C}_{4} & 0.221 \\ \mathrm{C}_{4} \mathrm{C}_{5} & 0.234 \\ \mathrm{C}_{5} \mathrm{C}_{6} & 0.874 \\ \mathrm{C}_{1} \mathrm{C}_{6} & 0.406 \\ \mathrm{C}_{1} \mathrm{O}_{7} & 0.566\end{array}$

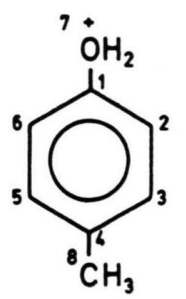
$\mathrm{C}_{1} \quad 0.254$
$\mathrm{C}_{2}-0.058$
0.054
0.043
0.054
$-0.059$
$-0.258$
0.007

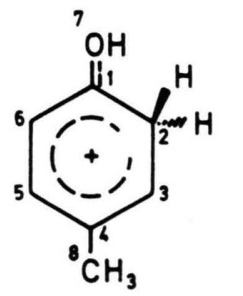

$\begin{array}{lr}\mathrm{C}_{1} & 0.591 \\ \mathrm{C}_{2} & -0.055 \\ \mathrm{C}_{3} & 0.059 \\ \mathrm{C}_{4} & -0.025 \\ \mathrm{C}_{5} & 0.241 \\ \mathrm{C}_{6} & -0.234 \\ \mathrm{O}_{7} & -0.357 \\ \mathrm{C}_{8} & 0.064\end{array}$

$\begin{array}{ll}\mathrm{C}_{1} \mathrm{C}_{2} & 0.240\end{array}$

$\mathrm{C}_{2} \mathrm{C}_{3} \quad 0.226$

$\mathrm{C}_{3} \mathrm{C}_{4} \quad 0.879$

$\begin{array}{ll}\mathrm{C}_{4} \mathrm{C}_{5} & 0.387\end{array}$

$\mathrm{C}_{5} \mathrm{C}_{6} \quad 0.777$

$\begin{array}{ll}\mathrm{C}_{1} \mathrm{C}_{6} & 0.522 \\ \mathrm{C}_{1} \mathrm{O}_{7} & 0.578\end{array}$

$\begin{array}{ll}\mathrm{C}_{1} \mathrm{C}_{2} & 0.657 \\ \mathrm{C}_{2} \mathrm{C}_{3} & 0.667 \\ \mathrm{C}_{3} \mathrm{C}_{4} & 0.654 \\ \mathrm{C}_{4} \mathrm{C}_{5} & 0.645 \\ \mathrm{C}_{5} \mathrm{C}_{6} & 0.675 \\ \mathrm{C}_{1} \mathrm{C}_{6} & 0.645 \\ \mathrm{C}_{1} \mathrm{O}_{7} & 0.158 \\ & \\ & \\ & \\ \mathrm{C}_{1} \mathrm{C}_{2} & 0.240 \\ \mathrm{C}_{2} \mathrm{C}_{3} & 0.226 \\ \mathrm{C}_{3} \mathrm{C}_{4} & 0.879 \\ \mathrm{C}_{4} \mathrm{C}_{5} & 0.387 \\ \mathrm{C}_{5} \mathrm{C}_{6} & 0.777 \\ \mathrm{C}_{1} \mathrm{C}_{6} & 0.522 \\ \mathrm{C}_{1} \mathrm{O}_{7} & 0.578\end{array}$


tral ring bonds and a decrease from $120^{\circ}$ (by $\sim 4^{\circ}$ ) of the $\mathrm{CC}_{\mathrm{CH}_{3}} \mathrm{C}$ angle. Both effects are compatible with decrease of the s-character in the carbon $\sigma$ orbitals directed from the methyl substituted carbon to the neighbouring carbons as compared with the corresponding hybrids in unsubstituted phenol. For instance, the carbon $\sigma$-orbitals directed from $\mathrm{C}_{4}$ to $\mathrm{C}_{5}$ and $\mathrm{C}_{3}$ in p-cresol have $\sim 32 \%$ s-character as compared with phenol where the same hybrids have $\sim 35 \%$ s-character. In this respect, the changes predicted by calculations reproduce qualitatively the essential features of the experimentally determined structures for cresols $2-4$ measured by X-ray diffraction [18].

As in the case of phenol, the structural changes of cresols upon protonation can be qualitatively interpreted in terms of rehybridization and changes in $\pi$-electron bond orders. In each case changes due to the oxygen protonation are more marked in the substituent fragment and in the part of the ring nearest to it, while the protonation in the ring produces a perturbation over the whole system. The calculated equilibrium geometries for bases 2-4, along with their oxonium and lowest energy benzenium ions are listed in Table 2.

Finally, we report in Table 3 the formal charge distribution and the $\pi$-overlap populations (for adjacent CC atoms only) for phenols 1-4 and their 0 -protonated and most stable ring protonated ions. Examination of the computed formal charges in the ring protonated ions vs. neutral base indicates that the positive charge of the added proton is centered predominantly on the $\mathrm{CH}_{2}$ group and on the carbon atom in the para position to the protonation site. A lesser amount of positive charge is transfered to the $\mathrm{CH}$ fragment in the ortho positions to the protonated carbon and to the $\mathrm{OH}$ group. For instance, the increase in formal charge for para protonated phenol $(\mathbf{1 d})$ is $0.15 e$ for the two $\mathrm{H}$-atoms of the $\mathrm{CH}_{2}$ group, $0.06 e$ for the carbon atom of the $\mathrm{CH}_{2}$ group, $0.23 e$ for $\mathrm{C}_{1}$ and $0.17 e$ for each of the $\mathrm{CH}$ fragments at the positions 3 and 5 . The $\mathrm{OH}$ group takes a share of $0.16 e$. The present results for cresols are in good accordance with the STO-3G results of Bursey et al. [5], with one notable exception. This is the case of charge distribution in the $\mathrm{CH}_{2}$ group. Namely, while STO-3G indicates an increase of the negative charge at the protonated carbon, relative to the parent compound, $\mathrm{MINDO} / 3$ predicts a slight decrease.

Protonation on oxygen produces an increase of positive charge for all ring positions except for the ring carbon attached to the $\mathrm{OH}$ group. The highest increment of positive charge occurs at the para ring position and the smallest at the meta position, in agreement with the results from NMR measurements [19].

\section{Proton Affinities}

The computed heats of formation of phenols 1-4 and their conjugate acids are summarized in Table 4, together with the experimental values for neutral

\begin{tabular}{|c|c|c|c|c|}
\hline Molecule or ion & SH $/ \mathrm{kcal} \mathrm{mol}^{-1}$ & ${ }^{7} \mathrm{OH}$ & ${ }^{7}$ & (1) \\
\hline Neutral & $\begin{array}{c}-29.2 \\
(-23.0)^{\mathrm{a}}\end{array}$ & $\begin{array}{l}-34.6 \\
(-30.7)^{\mathrm{a}}\end{array}$ & $\begin{array}{c}-35.1 \\
(-31.6)^{\mathrm{a}}\end{array}$ & $\begin{array}{c}-35.4 \\
(-30.0)^{\mathrm{a}}\end{array}$ \\
\hline $\begin{array}{c}\text { Protonated } \\
\text { at } \mathrm{C}_{1} \\
\mathrm{C}_{2} \\
\mathrm{C}_{3} \\
\mathrm{C}_{4} \\
\mathrm{C}_{5} \\
\mathrm{C}_{6} \\
\mathrm{O}_{7}\end{array}$ & $\begin{array}{l}160.2 \\
131.2 \\
149.3 \\
127.6 \\
149.3 \\
131.2 \\
143.8\end{array}$ & $\begin{array}{l}150.5 \\
130.4 \\
139.9 \\
121.5 \\
137.8 \\
126.0 \\
137.7\end{array}$ & $\begin{array}{l}153.2 \\
123.1 \\
147.2 \\
119.1 \\
141.3 \\
122.6 \\
136.7\end{array}$ & $\begin{array}{l}151.5 \\
123.9 \\
138.8 \\
126.2 \\
138.8 \\
123.9 \\
136.8\end{array}$ \\
\hline Proton affinities & 183.8 & 184.5 & 186.4 & 181.1 \\
\hline
\end{tabular}

Table 4. Calculated (observed) heats of formation of phenols 1-4 and their protonated ions. a Experimental values are
taken from [20]. 
phenol [20]. The calculated heats of formation are too positive throughout, being in every case within the expected MINDO $/ 3$ mean error of $6.8 \mathrm{kcal} / \mathrm{mol}$ for molecules containing oxygen [21]. It should be noticed, however, that calculations do not reproduce the correct order of the cresols stability. Starting from the computed heats of formation we have also calculated the proton affinities for all individual positions of the studied bases. The highest proton affinity obtained for a given base is conventionally considered as the proton affinity of that base. Calculated proton affinities are shown graphically in Figure 1.

A survey of the data present 2 d in Table 4 shows a predominance of the ring protonation for all four phenols. In each case, protonation in the para posi-

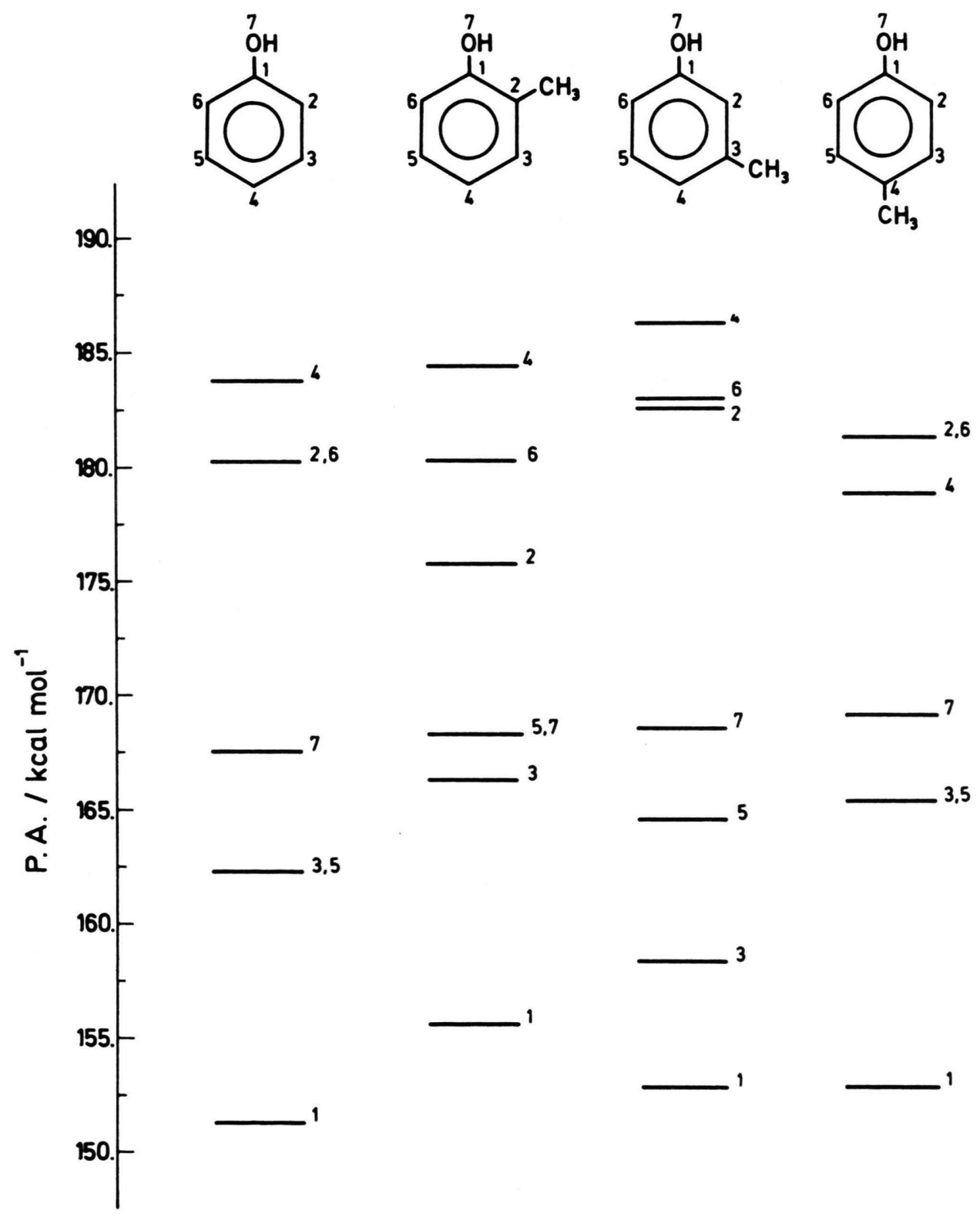

Fig. 1. Proton affinities for oxygen and ring carbons of bases $1-4$ as calculated by MINDO/3. Numbers indicate the position of protonation. 
tion to the hydroxy group is most favored, except for the p-cresol, where protonation ortho to the hydroxy group is predicted, in agreement with experimentally determined protonation sites in most superacid media [1-4].

The MINDO/3 calculated difference in stabilities between ions protonated on oxygen and the most stable ring protonated ion is in satisfactory agreement with the experimentally determined value of $15.0 \mathrm{kcal} / \mathrm{mol}$ obtained by Freiser et al. [22] by an deuterium exchange ICR experiment for phenol. The calculations of De Frees et al. [6] employing the idea of isodesmic reactions gave the same result $(14.9 \mathrm{kcal} / \mathrm{mol})$. The only experimental finding that contradicts preference of ring over oxygen protonation for related bases is that of Martinson and $\mathrm{Bu}$ trill [23]. They concluded from nonequilibrium $\mathrm{H}_{2} \mathrm{O}$ chemical ionization mass spectrometry studies that protonation of phenol occurs at the oxygen rather than in the ring, presumably due to the additional stabilization of oxonium ion provided by hydrogen bonding of the highly positive hydrogen atoms bound to oxygen in this ion.

The calculated proton affinity for phenol of $183.8 \mathrm{kcal} / \mathrm{mol}$ lies about $6 \%$ below the experimental value of $195.0 \mathrm{kcal} / \mathrm{mol}$ [22]. Since, we are not aware of any experimental determination of gas proton affinities for cresols we compared the calculated proton affinities for these bases with previously reported STO-3G values of Bursey et al. [5]. They reported values of $241.9,246.0$ and $241.8 \mathrm{kcal} /$ mol for the proton affinities of cresols 2,3 , and 4 , respectively. As anticipated, the proton affinities

[1] For review see, D. M. Brouwer, E. L. Mackor, and C. MacLean in "Carbonium Ions" (Eds. G. A. Olah and P. v. R. Schleyer), Vol. 2., John Wiley, New York 1970.

[2] G. A. Olah and Y. K. Mo, J. Org. Chem. 38, 373 (1973).

[3] J. W. Larsen and M. Eckert-Maksić, Croat. Chem. Acta 45, 503 (1973).

[4] S. M. Blackstock, K. E. Richards, and G. J. Wright, Can. J. Chem. 52, 3313 (1974).

[5] M. M. Bursey, R. S. Greenberg, and L. G. Pedersen, Chem. Phys. Lett. 36, 470 (1975).

[6] D. J. Frees, R. T. McIver Jr., and W.J. Hehre, J. Amer. Chem. Soc. 99, 3853 (1977).

[7] J. Catalan and M. Yanez, J. Chem. Soc. Perkin II (1979) 741.

[8] M. Eckert-Maksić and Z. B. Maksić, J. Chem. Soc. Perkin II (1981) 1462.

[9] R. C. Bingham, M. J. S. Dewar, and D. H. Lo, J. Amer. Chem. Soc. 97, 1285 (1975). Version QCPE 12, 383 (1979) was used. calculated by MINDO/3 are substantially lower. Since STO-3G estimates of the proton affinities for related bases are usually to high by about $25 \%$ [24], the present results should be closer to the real values. Both approaches, MINDO/3 and STO-3G, however, give the same order of proton affinities for cresols, the meta isomer possessing the highest proton affinity.

We can conclude that MINDO/3 results reflect fairly well most of the experimental features observed in the protonation of phenol and cresols under superacidic as well as gas phase conditions. Thus, the calculated structural parameters of ring protonated ions formed upon protonation are consistent with the experimentally determined benzenium ion structures. The stability order of conjugate acids formed upon their protonation represent fairly well the positional selectivity in the protonation reactions in strong acids. The calculated changes in electron densities induced by protonation reproduce qualitatively the changes in the ${ }^{13} \mathrm{C}$ NMR chemical shifts of the studied bases. From a comparison of the calculated proton affinity for phenol with the experimentally determinated value it can be inferred that the experimental proton affinities of the studied bases are probably $\sim 10 \%$ higher than the theoretically estimated values.

\section{Acknowledgement}

This research was financially supported by the Self-managing Authority for Scientific Research of the SR of Croatia (SIZ II).

[10] T. Pedersen, N. W. Larsen, and L. Nygaard, J. Mol. Structure 4, 59 (1969).

[11] A. Domenicano, A. Vaciago, and C. A. Coulson, Acta Crystallogr. Sect. B31, 221, 1631 (1974); B35, 1382 (1979).

[12] A. Domenicano, P. Mazzeo, and A. Vaciago, Tetrahedron Letters (1976), p. 1029.

[13] C. Trindle and O. Sinanoglu, J. Amer. Chem. Soc. 91, 853 (1969).

[14] Z. B. Maksić and M. Randić, J. Amer. Chem. Soc. 95, 6522 (1973).

[15] H. A. Bent, Chem. Rev. 61, 276 (1961).

[16] A. D. Walsh, Discuss. Faraday Soc. 2, 18 (1947).

[17] N. C. Baenziger and H. D. Nelson, J. Amer. Chem. Soc. 90, 6602 (1968).

[18] C. Bois, Acta Crystallogr. B 26, 2086 (1970); B 28, 25 (1972); B 29, 1011 (1973).

[19] G. L. Nelson, G. C. Levy, and J. D. Cargioli, J. Amer. Chem. Soc. 94, 3089 (1972). 
[20] J. L. Franklin, J. G. Dillard, H. M. Rosenstock, J. T. Herron, K. Draxl, and F. H. Field, Ionization Potentials and Heats of Formation of Gaseous Positive Ions, NSRDS-NBS 26, US Govt. Printing Office, Washington 1969

[21] R. C. Bingham, M. J. S. Dewar, and D. H. Lo, J. Amer. Chem. Soc. 97, 1302 (1975).
[22] B. S. Freiser, R. L. Woodin, and J. L. Beauchamp, J. Amer. Chem. Soc. 97, 6893 (1975).

[23] D. P. Martinson and S. E. Butrill, Org. Mass. Spectrometry, 11, $762(1976)$.

[24] W. J. Hehre and J. A. Pople, J. Amer. Chem. Soc. 94, 6901 (1972). 